\title{
Studying the dynamic of a high alpine catchment based on multiple natural tracers - Supplementary Material
}

Anthony Michelon ${ }^{1}$, Natalie Ceperley ${ }^{2}$, Harsh Beria ${ }^{3}$, Joshua Larsen ${ }^{4}$, Torsten Vennemann ${ }^{1}$, Bettina Schaefli ${ }^{1,2}$

${ }^{1}$ Institute of Earth Surface Dynamic (IDYST), Faculty of Geosciences and Environment (FGSE), University of Lausanne, Lausanne, Switzerland

${ }^{2}$ Institute of Geography (GIUB) and Oeschger Center of Climate Change Research (OCCR), University of Bern, Bern, Switzerland. Bettina Schaefli: Institute of Geography

${ }^{3}$ Department of Environmental Systems Science, ETH Zurich, Zurich, Switzerland

${ }^{4}$ School of Geography, Earth and Environmental Sciences, University of Birmingham, Birmingham, UK

Correspondence to: Bettina Schaefli (bettina.schaefli@giub.unibe.ch)

\section{Summary:}

This document contains pictures of the Vallon de Nant catchment (Figure S1 and Figure S2) and gauging station at the outlet (Figure S3). Next the Figure S4 shows the hypsometric curve of the Vallon de Nant. The Figure S5 present three along stream streamflow measurements, and the Figure S6 the location of all sources in the catchment. The Figure S7 presents a comparison of the electric conductivity of water samples when they were sample in the field and measured in the lab months after. Figure S8 combine time series of water table depth and temperature at PZ1 and PZ2.

The Table S1 resume the start and end dates of each hydrological period, and the Table S2 the start and end dates of each snowcover period at the soil temperature points. 

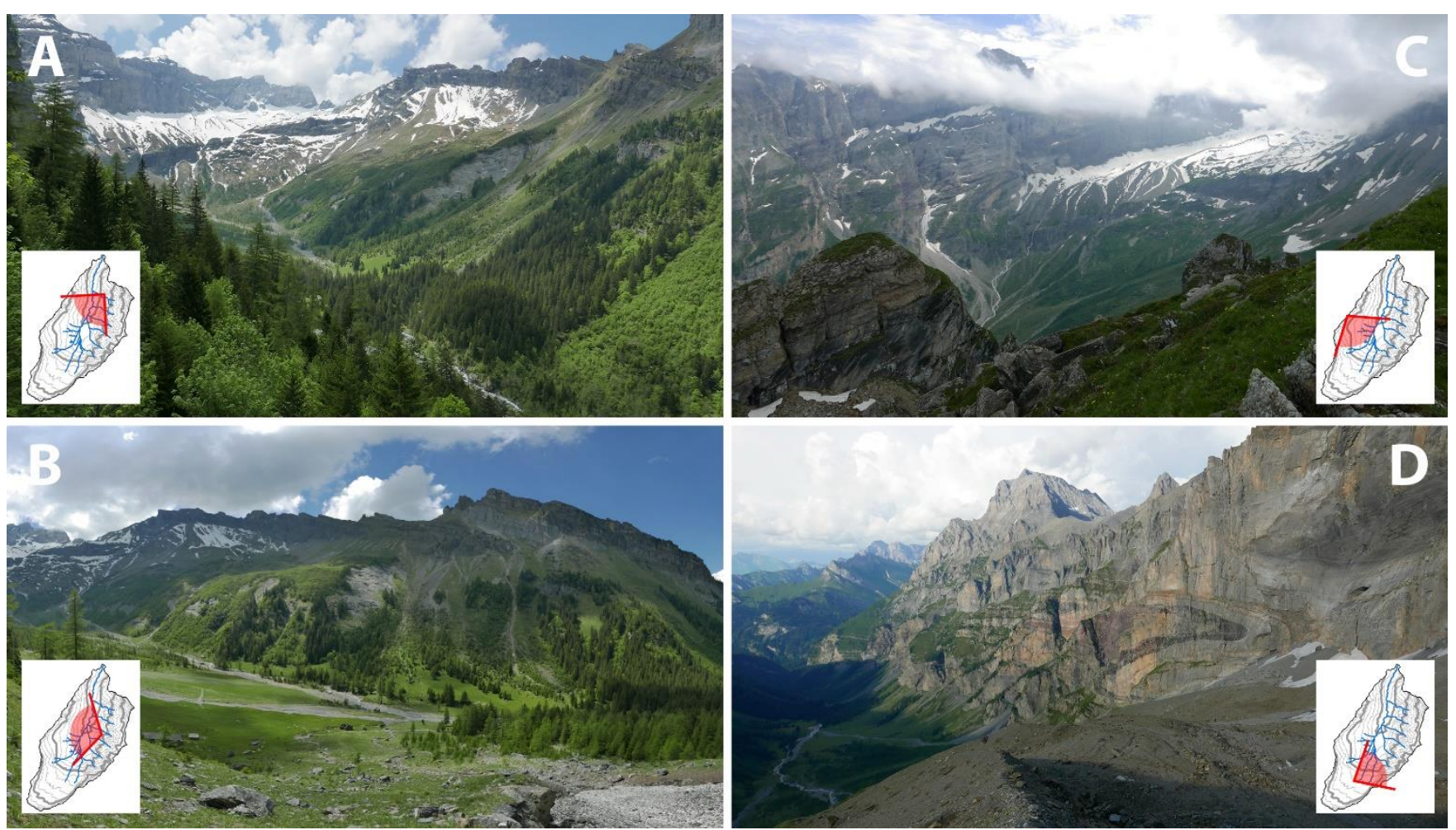

Figure S1. Pictures of the Vallon de Nant. 

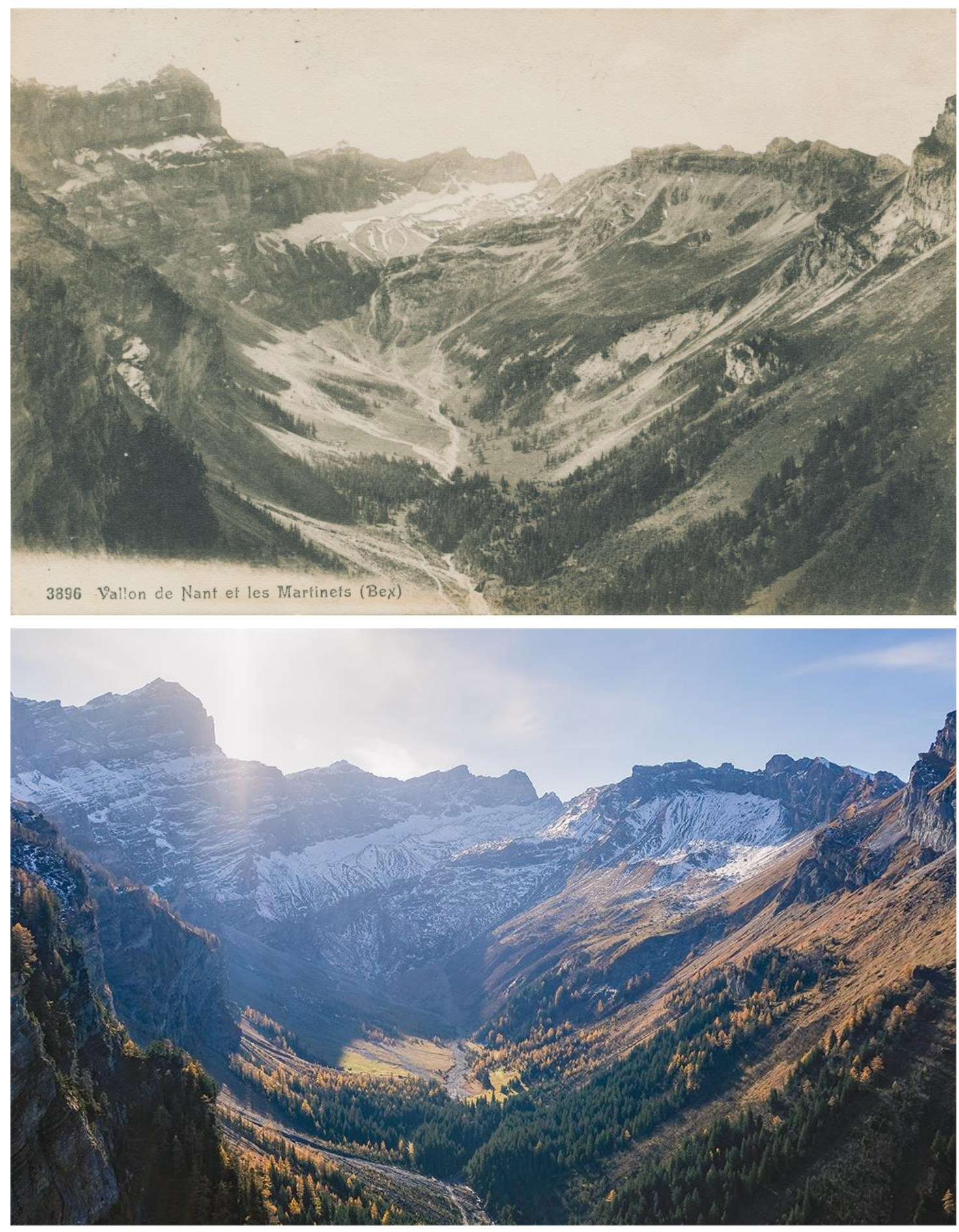

Figure S2. Comparison of vegetation cover between a historical picture (1912 or before, on top) and an actual picture (2017, on bottom). Credit for the top picture: Robert di Salvo 


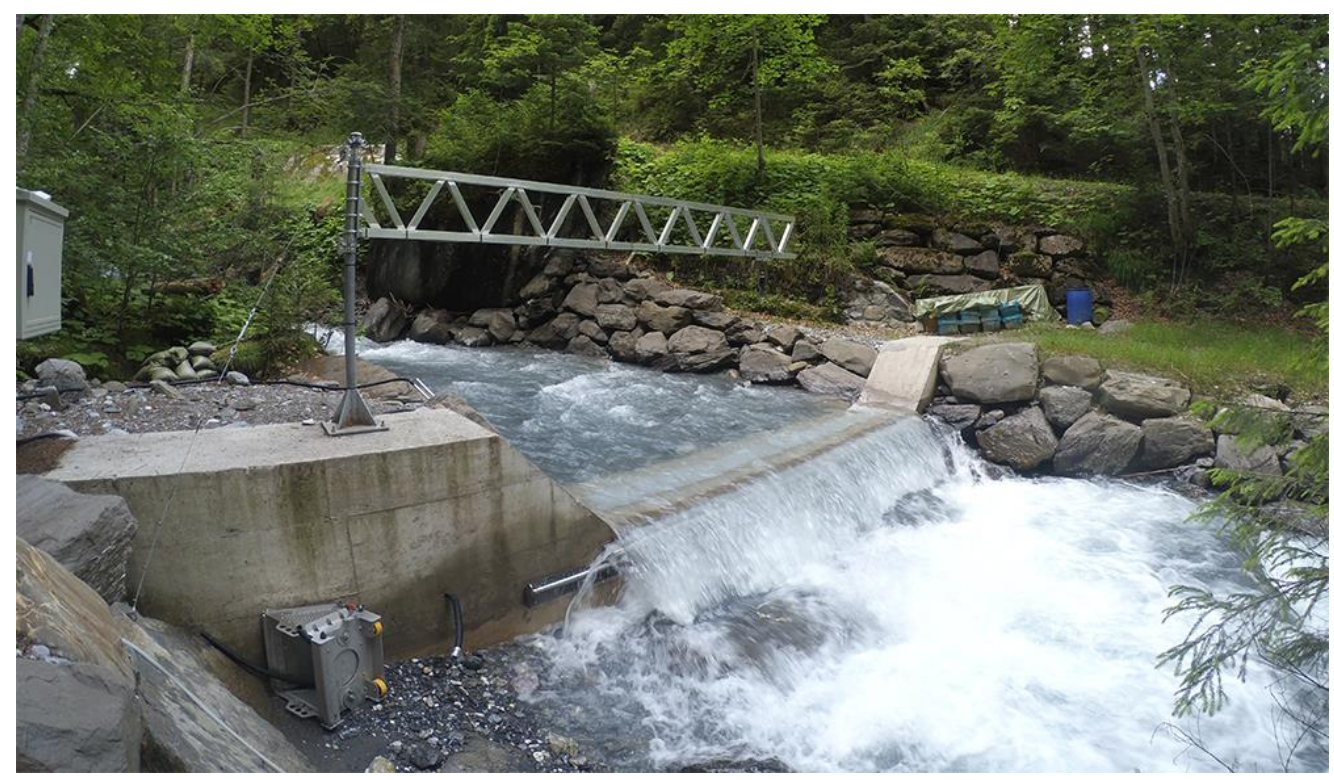

Figure S3. River stage measure at the outlet. The streamflow is here measured between 0.96 and $1.13 \mathrm{~m}^{3} \cdot \mathrm{s}^{-1}$. 


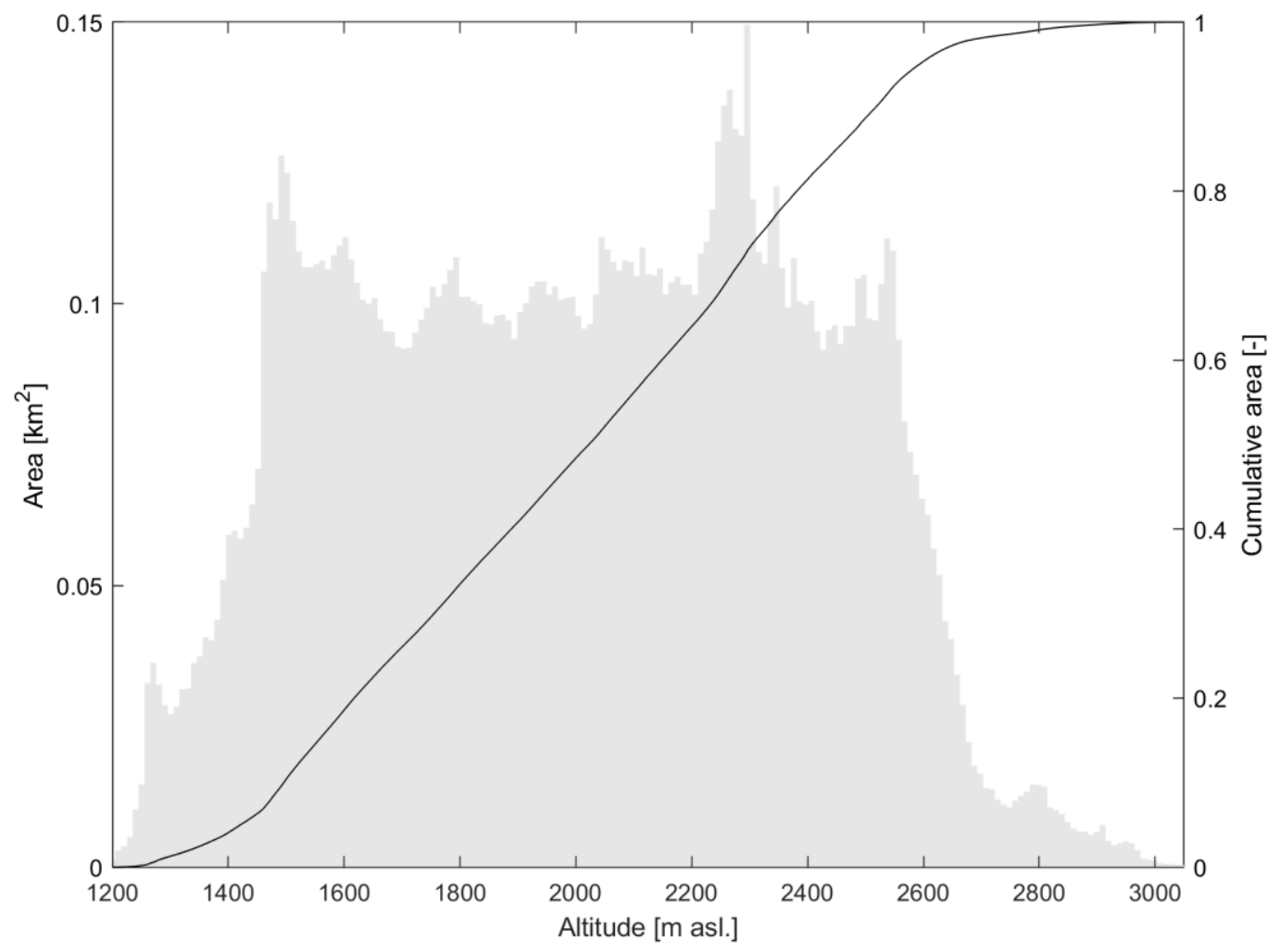

Figure S4. Hypsometric curve of the Vallon de Nant. 

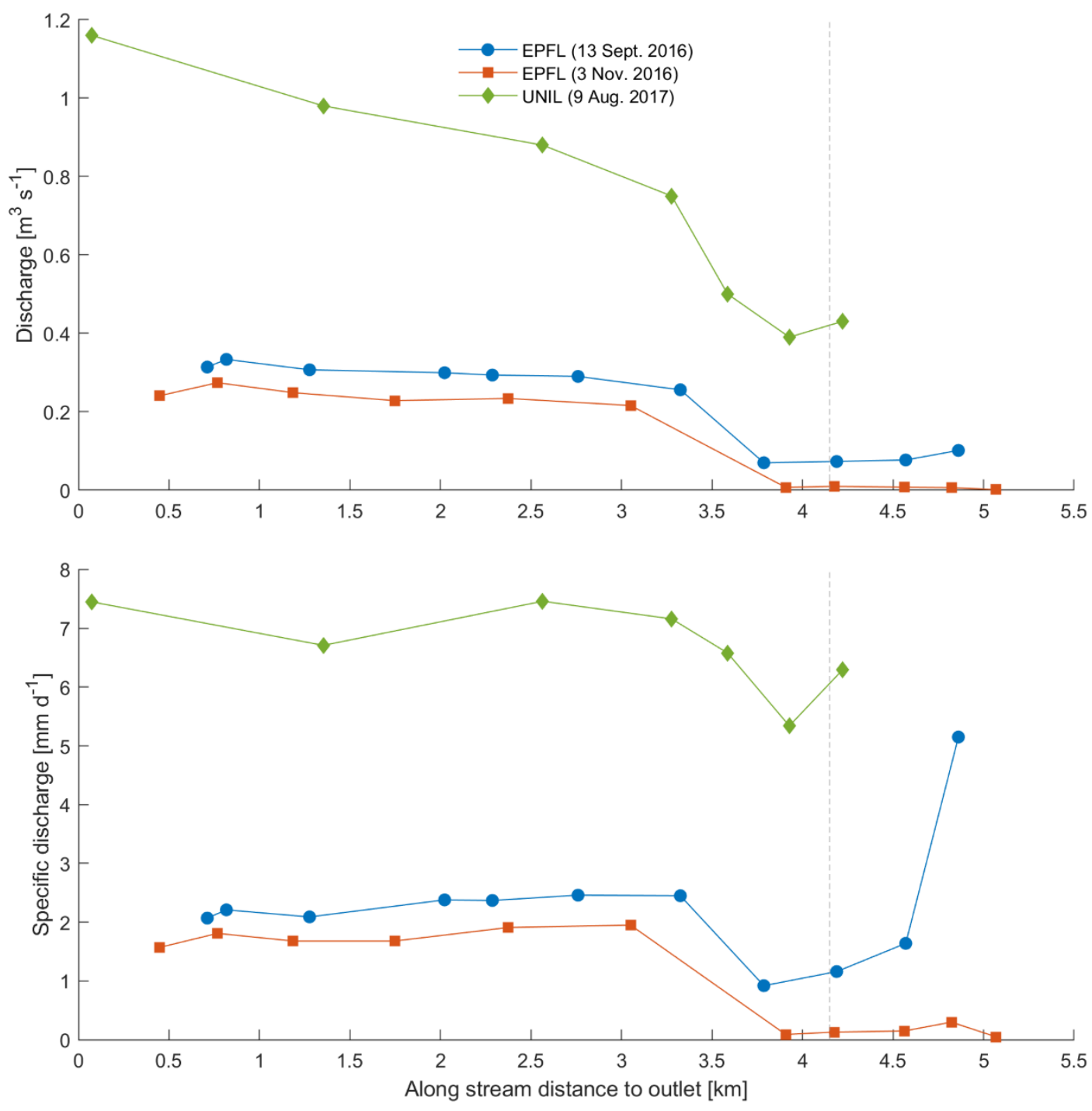

Figure S5. Discharge (top) and specific discharge (bottom) along the main stream measured by the Stream Biofilm and Ecosystem Research Laboratory group (EPFL) and the Catchment hydrology group (UNIL). The mean specific discharge measured at the outlet during the measures was $2.2 \mathrm{~mm} \mathrm{~d}^{-1}\left(1.7\right.$ to $\left.2.8 \mathrm{~mm} \mathrm{~d}^{-1}\right)$ on 13 Sept. $2016,2.0 \mathrm{~mm}$ $\mathrm{d}^{-1}\left(1.5\right.$ to $\left.2.5 \mathrm{~mm} \mathrm{~d}^{-1}\right)$ on 3 Nov. 2016 , and $3.6 \mathrm{~mm} \mathrm{~d}^{-1}$ (2.9 to $\left.4.4 \mathrm{~mm} \mathrm{~d}^{-1}\right)$ on 9 Aug. 2017. The vertical line at 4.15 $\mathrm{km}$ shows the stream network node beyond which the followed path diverges between the main stream ( 3 Nov. 2016) and an affluent (13 Sept. 2016 and 9 Aug. 2017). 


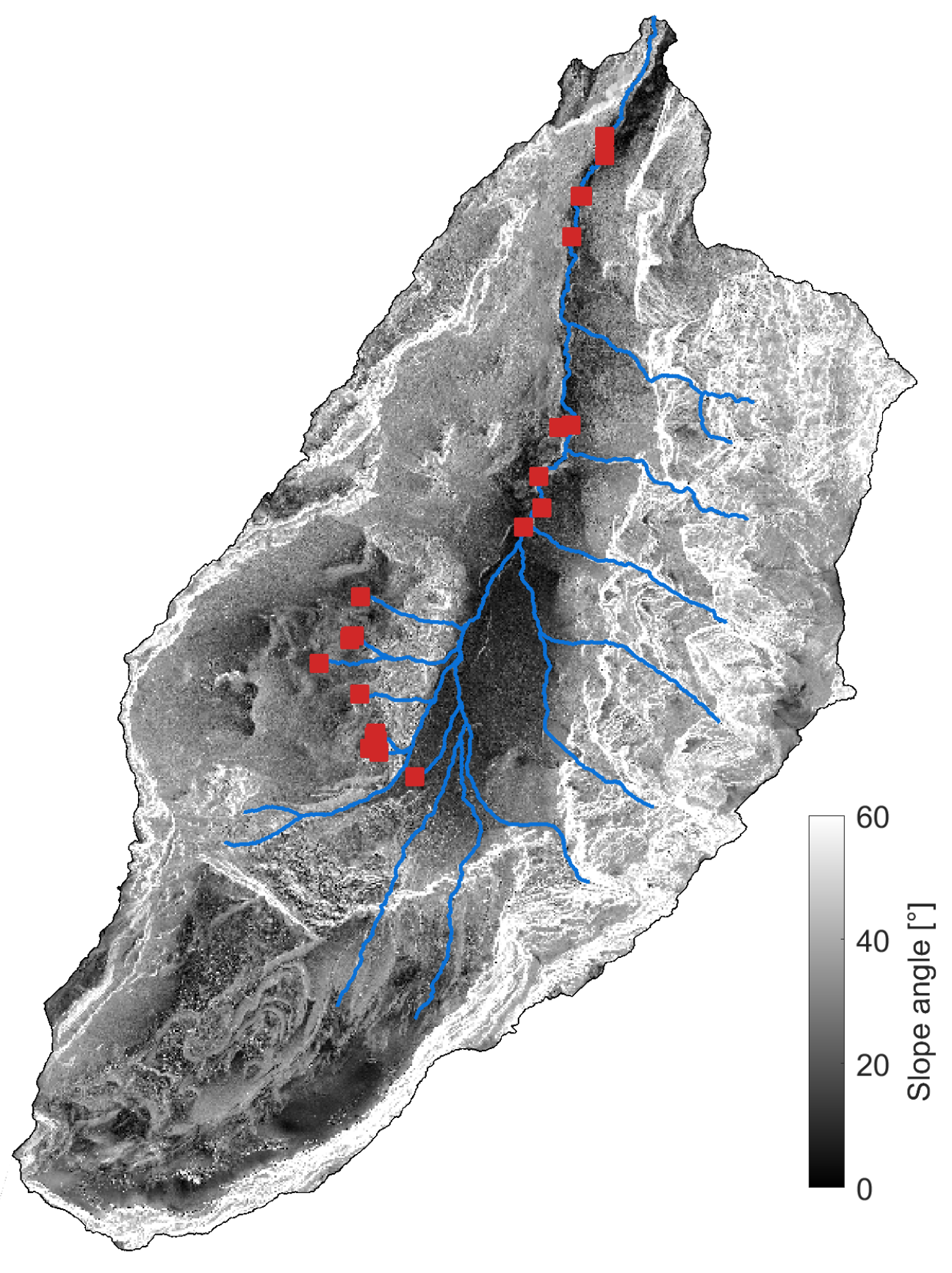

Figure S6. Location of all the springs (red square dots) in the Vallon de Nant. The slopes calculation is based on a digital elevation model at a resolution of $2 \mathrm{~m}$ (swissAlti3D, 2012). 


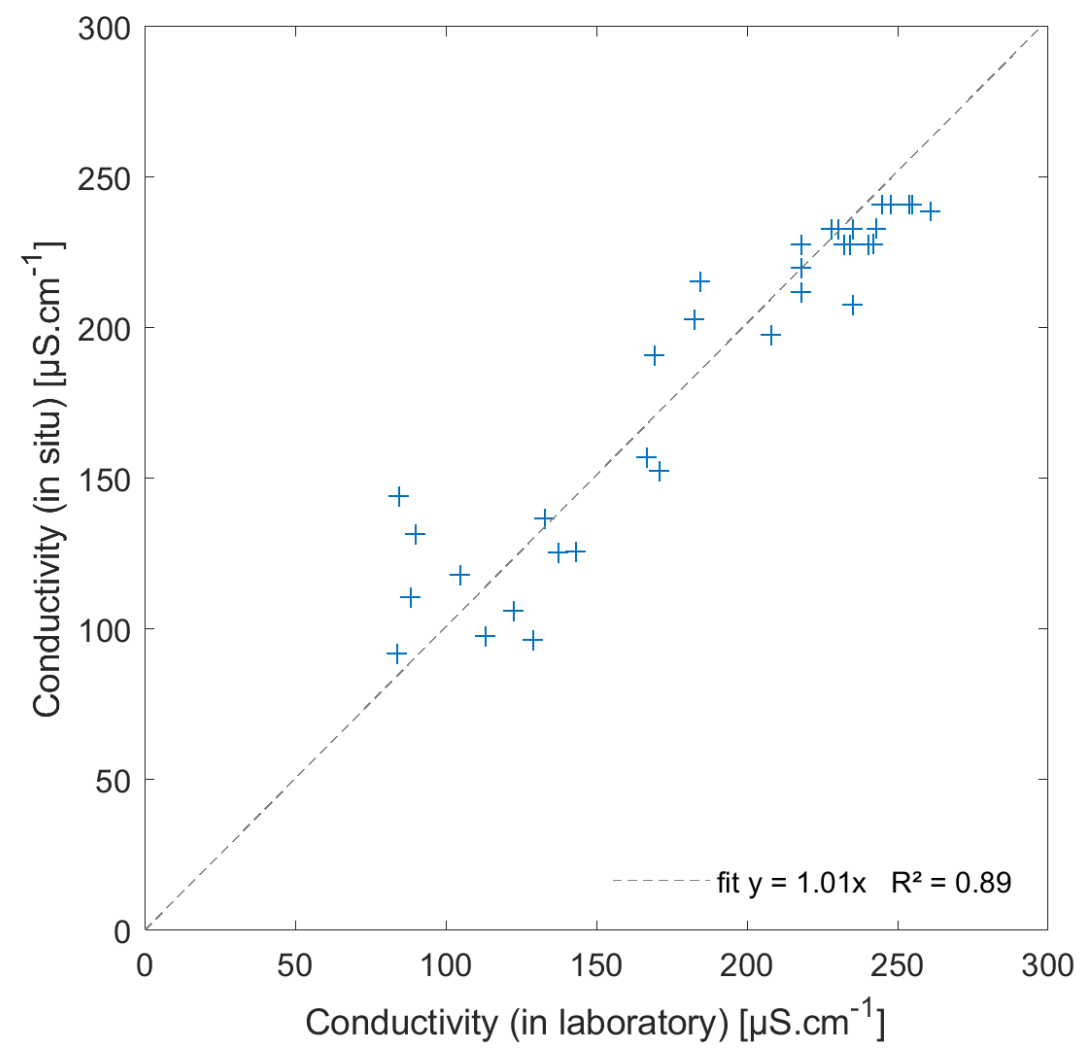

Figure S7. Comparison of 38 samples conductivity measured on the field using a WTW Multi 3510 IDS with a WTW TetraCon 925 probe (Xylem Analytics Germany Sales GmbH \& Co, Weilheim, Germany) or later in the laboratory directly within the $12 \mathrm{~mL}$ amber silicate vials using a JENWAY 4510 Conductivity Meter with a $6 \mathrm{~mm}$ glass probe (Stone, UK). 

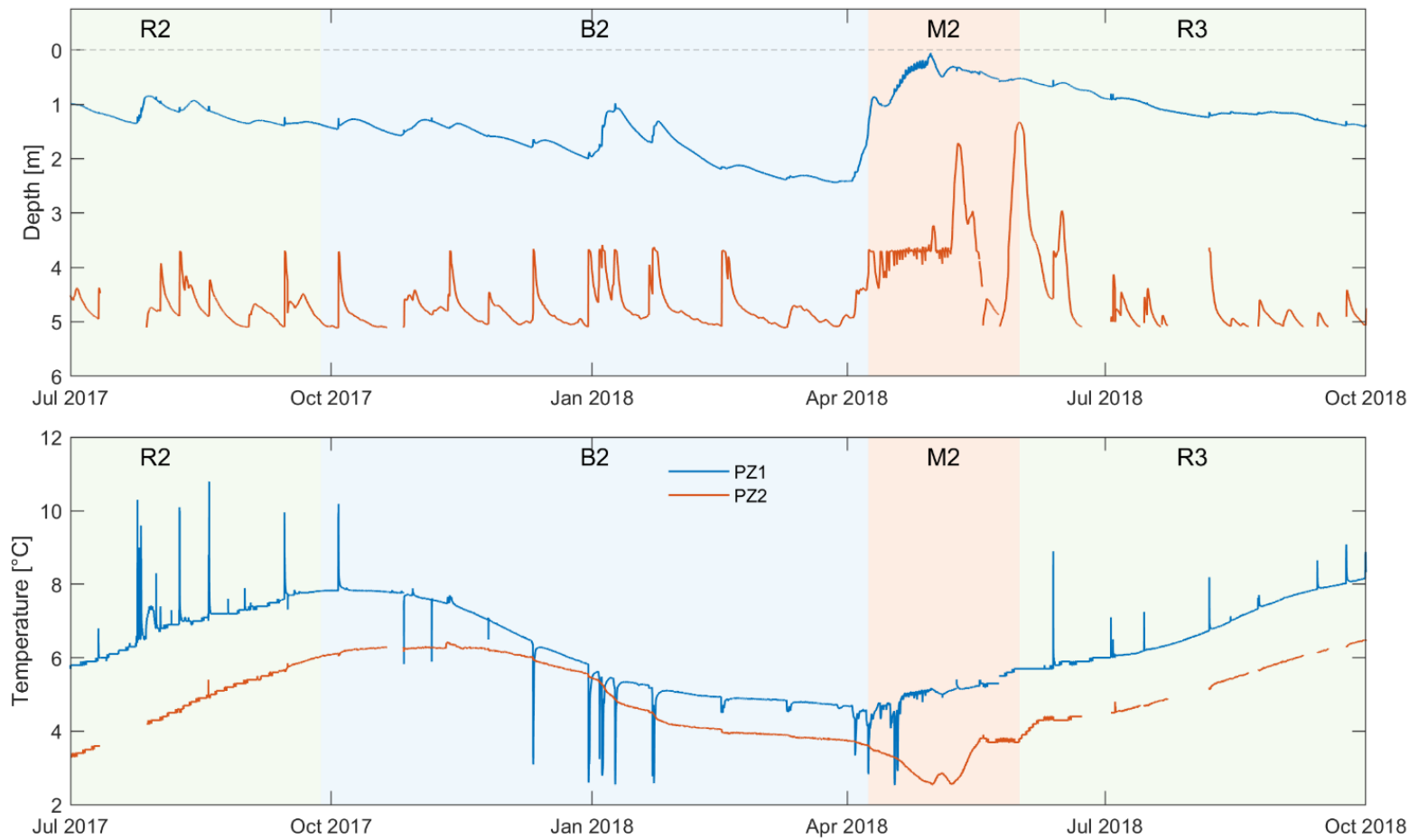

Figure S8. Water table depth (top) and temperature (bottom) at PZ1 and PZ2 from 1 July 2017 to 1 October 2018. Water table depth and temperature data are from Thornton et al. (2021). 
Table S1. Start and end dates of each hydrological period.

\begin{tabular}{ccc} 
Period & Start date & End date \\
\hline B0 & 1 January 2016 & 31 March 2016 \\
E0 & 31 March 2016 & 6 May 2016 \\
M0 & 6 May 2016 & 24 June 2016 \\
R1 & 24 June 2016 & 27 September 2016 \\
B1 & 27 September 2016 & 18 March 2017 \\
E1 & 18 March 2017 & 6 May 2017 \\
M1 & 6 May 2017 & 2 June 2017 \\
R2 & 2 June 2017 & 27 September 2017 \\
B2 & 27 September 2017 & 8 April 2018 \\
M2 & 8 April 2018 & 31 May 2018 \\
R3 & 31 May 2018 & 1 January 2019
\end{tabular}


Table S2. Start and end dates of each snowcover period at the soil temperature points.

\begin{tabular}{lcc} 
Soil temperature site & Start date & End date \\
\hline $1240 \mathrm{~m}$ asl. & $3 / 2 / 2016$ & $16 / 3 / 2016$ \\
& $4 / 1 / 2017$ & $13 / 3 / 2017$ \\
& $25 / 11 / 2017$ & $7 / 4 / 2018$ \\
$1530 \mathrm{~m}$ asl. & $1 / 1 / 2016$ & $14 / 5 / 2016$ \\
& $4 / 1 / 2017$ & $9 / 5 / 2017$ \\
$2640 \mathrm{~m}$ asl. & $5 / 11 / 2017$ & $29 / 5 / 2018$ \\
& $1 / 1 / 2016$ & $9 / 7 / 2016$ \\
& $4 / 10 / 2016$ & $25 / 11 / 2016$ \\
& $4 / 1 / 2017$ & $13 / 6 / 2017$ \\
& $22 / 10 / 2017$ & $6 / 6 / 2018$
\end{tabular}




\section{REFERENCES}

swissAlti3D: The digital elevation model of Switzerland, 2012.

Thornton, J. M., Brauchli, T., Mariethoz, G., and Brunner, P.: Efficient multi-objective calibration and uncertainty analysis of distributed snow simulations in rugged alpine terrain, Journal of Hydrology, 126241, https://doi.org/10.1016/j.jhydrol.2021.126241, 2021. 